\title{
One year Survival Rate of Ketac Molar versus Vitro Molar for Occlusoproximal ART Restorations: a RCT
}

\section{Anna Luisa de Brito PACHECO(a) Isabel Cristina OLEGÁRIO(b) Clarissa Calil BONIFÁCIO(c) Ana Flávia Bissoto CALVO(b) José Carlos Pettorossi IMPARATO(b) Daniela Prócida RAGGIO(b)}

(a)Faculdade São Leopoldo Mandic, Faculty of Odontology, Dental Research Center, Campinas, SP, Brazil.

(b) Universidade de São Paulo - USP, Dental School, Orthodontics and Pediatric Dentistry Department, São Paulo, SP, Brazil.

(c)Academic Centre for Dentistry Amsterdam - ACTA, Department of Cariology, Endodontics and Pedodontology, Amsterdam, The Netherlands.
Declaration of Interests: The authors certify that they have no commercial or associative interest that represents a conflict of interest in connection with the manuscript.

Corresponding Author:

Daniela Prócida Raggio

E-mail:danielar@usp.br

https://doi.org/10.1590/1807-3107BOR-2017.vol31.0088

Submitted: Mar 02, 2017

Accepted for publication: Sept 11, 2017

Last revision: Sept 15, 2017
Abstract: Good survival rates for single-surface Atraumatic Restorative Treatment (ART) restorations have been reported, while multi-surface ART restorations have not shown similar results. The aim of this study was to evaluate the survival rate of occluso-proximal ART restorations using two different filling materials: Ketac Molar EasyMix (3M ESPE) and Vitro Molar (DFL). A total of 117 primary molars with occluso-proximal caries lesions were selected in 4 to 8 years old children in Barueri city, Brazil. Only one tooth was selected per child. The subjetcs were randomly allocated in two groups according to the filling material. All treatments were performed following the ART premises and all restorations were evaluated after 2, 6 and 12 months. Restoration survival was evaluated using Kaplan-Meier survival analysis and Log-rank test, while Cox regression analysis was used for testing association with clinical factors $(\alpha=5 \%)$. There was no difference in survival rate between the materials tested, $(\mathrm{HR}=1.60, \mathrm{CI}=0.98-2.62, \mathrm{p}=0.058)$. The overall survival rate of restorations was $42.74 \%$ and the survival rate per group was Ketac Molar $=50,8 \%$ and Vitro Molar G2 $=34.5 \%$ ). Cox regression test showed no association between the analyzed clinical variables and the success of the restorations. After 12 months evaluation, no difference in the survival rate of ART occluso-proximal restorations was found between tested materials.

Keywords: Glass Ionomer Cements; Pediatric Dentistry; Tooth, Deciduous.

\section{Introduction}

Atraumatic Restorative Treatment (ART) is a minimally intervention approach that involves preventive measures, sealing and fillings cavities. The restorative technique requires the removal of softened and demineralized dentine (infected dentin) with hand instruments followed by a restoration with an adhesive material. ${ }^{1,2}$

ART is recommended by the World Health Organization for bringing restorative care to people without access to dental attention. ${ }^{2}$ The indication of ART was initially restricted to the treatment of teeth with cavities that, with no other treatment available, would lead to tooth extraction in less privileged communities in developing countries. The successful treatment of these teeth, through high-quality restorations, led to questioning if the ART approach could bring benefits to dental treatments in developed countries. ${ }^{3}$ The extension of ART indications is 
due to the fact that it is now considered a high-quality approach and can be applied to everyone, regardless of their economic or social situation, ${ }^{4,5}$ enlarging the access to dental treatment.

The indicated material for ART is high viscosity glass ionomer due to physical and chemical properties, such as the adhesion to tooth structure, biocompatibility, chemical setting reaction and the development and release of fluoride, which give it preventive characteristics. ${ }^{6,7,8}$

The high viscosity glass ionomer cements have been specially developed for ART, since they have improved mechanical properties, resulting in higher longevity of sealants and restorations, both in permanent and deciduous teeth. ${ }^{9,10}$ The literature shows a large heterogeneity in the survival rates of occluso-proximal ART restorations in primary teeth after one year, ranging from 31 to $100 .{ }^{9}$ However, a recent systematic review and meta-analysis showed that the longevity of those restorations is similar to conventional treatment, with a good level of evidence. ${ }^{11}$ There is a large variation between the costs of high viscosity glass ionomers currently used in ART. There are new products on the market, some being produced in Brazil and sold in Latin America, which are also indicated for ART with a lower cost when compared to other GICs. Thus, it is important to investigate the longevity of restorations using Brazilian brands compared with a material that already has literature data, and can be considered a control. Ketac Molar has already been widely researched and has good results, whereas Vitro Molar has only been reported by few in vitro studies, ${ }^{12,13,14,15}$ but not clinical trials.

The aim of this study was to evaluate the survival rate of occluso-proximal ART restorations with two glass ionomer cements suitable for this technique: Ketac Molar (3M ESPE) and Vitro Molar (Nova DFL) after 12 months of evaluation.

\section{Material and Methods}

\section{Trial design}

This is a two-arm parallel-randomized clinical trial. This study was registered at the Clinical Trials website under the registration number NCT02267720.
The report followed the CONSORT (Consolidated Standards of Reporting Trials) guideline.

\section{Sample size and selection}

The sample size was calculated considering a success rate for occluso-proximal ART restorations of $50 \%$ and an acceptable minimum difference of $30 \%$ in a superiority trial. Considering a type I error probability of $5 \%$ and a power of $80 \%$, adding an additional $20 \%$ for possible losses, a number of 58 restorations per group was reached. The experimental unit was the tooth thus only one tooth per patient was included in the study. According to the sample size calculation, 117 subjects were selected from 19 municipal schools in the city of Barueri, from ages 4 to 8 .

\section{Eligibility criteria}

The selection was made after visual examination of primary molars. Two examiners (ALBP and ICO), who participated in a supervised previous training at the Unviersidade de São Paulo for a week evaluating carious lesions, performed the visual evaluation screening. Only children whose guardians signed the consent form were examined. All subjects received instructions on oral health, particularly in relation to oral hygiene and sugar consumption.

The eligibility criteria were: children aged from 4 to 8 years old, in good general health and cooperative for dental exams. The guardians would have to accept and sign the consent form and the children would have to have at least one primary molar with occluso-proximal carious lesion.

The children included in this study contemplated the following inclusion criteria: presence of one primary molar with occluso-proximal carious lesion not exceeding $2 \mathrm{~mm}$ in the mesial-distal direction and $2.5 \mathrm{~mm}$ occlusal-gingivally and buccolingually. The exclusion criteria were: presence of pulp exposure, pain, mobility, presence of swelling or fistula near the tooth, not accessible carious lesion to hand instruments and the absence of the neighboring tooth.

When the child had more than one primary molar that could be included in the study, a draw was performed for selecting which one would be 
included in the study. All other treatments needs that couldn't be performed in the school (endodontic and extraction) were referred for the public health system in the city of Barueri.

The experimental groups, the materials used, as well as their manufacturers, are described in Table 1.

\section{Operators}

The operators were two undergraduate students, trained on how to perform ART restorations in primary molars. They underwent a week of training with patients at the Universidade de São Paulo, under the supervision of an experienced dentist in ART before starting the study (DPR). This project had the help of an auxiliary in oral health, provided by the city of Barueri, who was only responsible for handling the materials, not helping in children's care. This auxiliary had been trained on how to handle the materials used in this study according to the manufacturer's instructions.

One of the operators conducted 63 restorations and the other, 54 totaling 117 restorations. Each child was assigned to one of the two groups randomly, with a random list.

\section{Allocation concealment and blinding}

A double blind clinical study was set up. After randomization, to ensure allocation concealment, opaque envelopes were used. The envelope was open by the auxiliary who handed the material ready for use to the operators, after cavity preparation. The materials were not distinguishable by color, but the consistency was very different, so operators were not completely blinded regarding groups. The subjects were blinded regarding groups.

\section{Treatment procedure}

The subjetcs were treated during school hours in their respective schools in the city of Barueri. The

Table 1. Distribution of groups according to the material of the restoration.

\begin{tabular}{lccc}
\hline Groups & $\mathrm{n}$ & Material & Manufacturer \\
\hline Control & 59 & Ketac Molar $^{\circledR}$ & 3 M ESPE \\
Experimental & 58 & VitroMolar $^{\circledR}$ & Nova DFL \\
\hline
\end{tabular}

treatment was performed on school desks, with natural lighting and a coupled light on the forehead of the operator and following the steps recommended by Frencken et al. ${ }^{1}$

After the treatment, the variables related to the subject (sex and caries experience by DMFT/dmft) and to the restored tooth (arch, tooth, side, presence of saliva/blood contamination, occlusal and proximal contact after the restoration and cavity volume) were collected by the operator.

\section{Evaluation}

The restorations were evaluated after 2, 6 and 12 months. Two calibrated examiners carried out the evaluations. The evaluation was performed using Roeleveld et al. ${ }^{16}$ criteria. The width and depth of the marginal defects, surface wear and excess or lack of material were measured with the use of the CPI (Community Periodontal Index) periodontal probe, which has a ball tip with $0.5 \mathrm{~mm}$ diameter.

\section{Analysis}

The survival of the restorations was assessed by Kaplan-Meier survival analysis and log-rank test. To evaluate the association between the outcome and patient variables, Cox regression test was applied. The significance level for the tests was considered to be $5 \%$.

\section{Results}

In total, 548 children were examined from 4 to 8 years old from 19 public schools in the city of Barueri. 117 children fitted the sample inclusion criteria and were selected to participate in the study (Figure 1). All the children that were evaluated at least one time during the follow-up were included in the analysis and for this reason no child was considered a drop-out in this study.

The inter-examiner Kappa value was 0.89. Table 2 shows the descriptive and Cox regression univariated and adjusted analysis of the restorations. After the 12-month follow-up, the overall survival of the restorations was $42.74 \%$. The restorations that remained intact or had slight marginal defects or surface wear $(<0.5 \mathrm{~mm})$ without the need of repair 


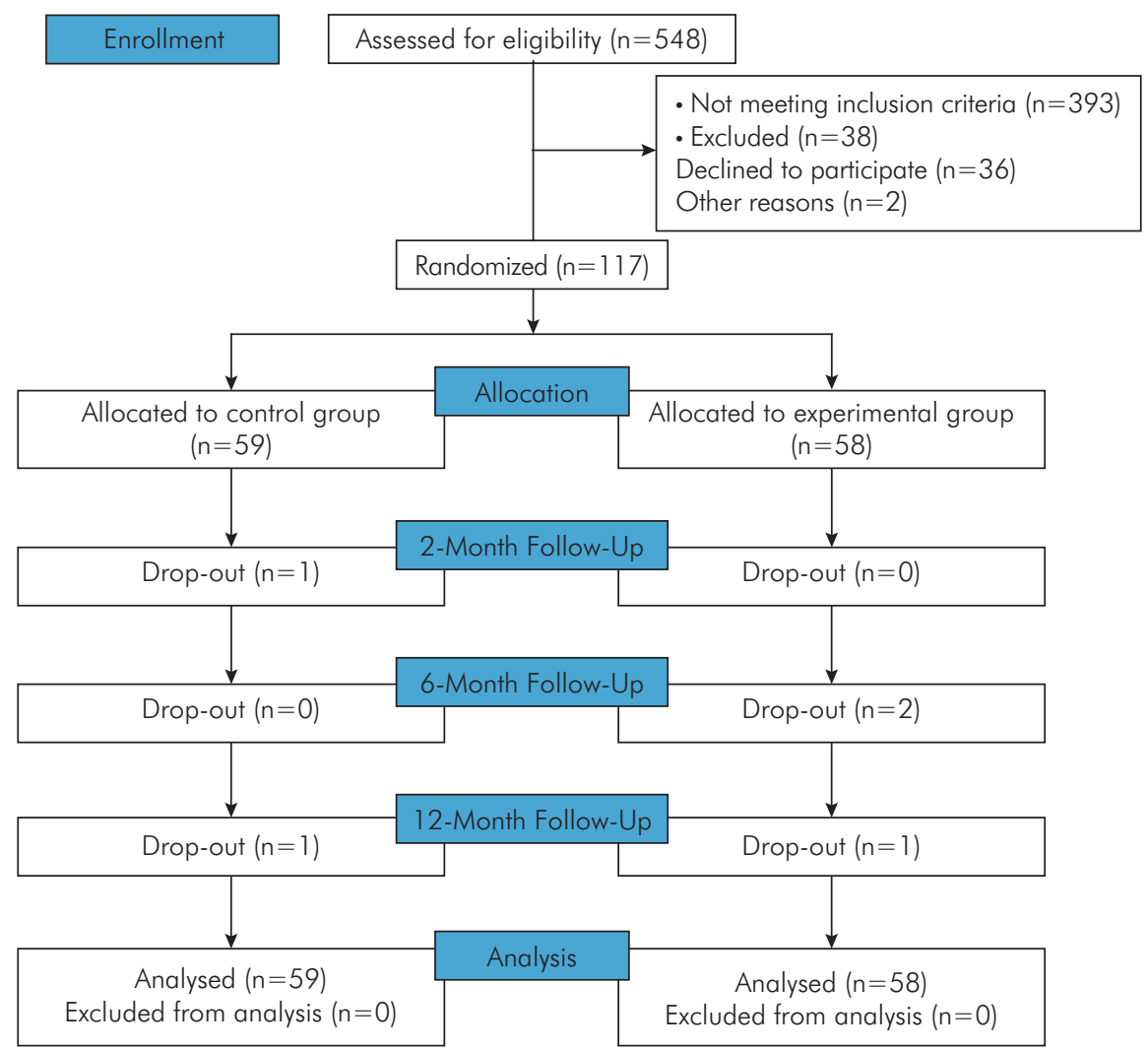

Figure 1. CONSORT flowchart of the participants' progress through the trial phases.

were considered successful (scores 00 and 10). The main reasons for failure of the restorations were: underfilled restorations $(>0.5 \mathrm{~mm})$ needing repair $(\mathrm{n}=4)$ and lack of restoration, bulk fracture or moving or partial loss needing repair $(\mathrm{n}=63)$.

The Kaplan-Meier survival analysis was carried out and can be observed in Figure 2.

\section{Discussion}

This randomized clinical study evaluated the longevity of occluso-proximal ART restorations with two different glass ionomer brands. After the 12-month follow-up, the overall survival of the restorations was $42.74 \%$. The success rates of Ketac Molar (3M ESPE) and Vitro Molar (Nova DFL) were $50.85 \%$ and $34.48 \%$, respectively. Although, the overall survival rate found is lower than that reported by two meta-analysis, ${ }^{9,10}$ we can observe that there is a great heterogeneity between the studies, even with inferior survival rates ( $30 \%$ after 1 year). ${ }^{9}$ Even though the values between the materials were numerically different, no statistical difference $(p=0.058)$ was observed in the first year of follow-up. Perhaps, with a longer follow-up period, a difference may be found. Therefore, a longer follow-up of those restorations is advised in order to ensure these findings.

Glass ionomer restorations can fail for various reasons, such as insufficient caries removal on cavity preparation, inadequate conditioning of the cavity and improper mixing of the restorative material. None of these conditions were registered at the time of restorations. The most common failures in this study were the lack of the restoration, bulk fracture or moving or partial loss needing repair $(n=63)$, which is according to another study that evaluated the longevity of restorations. ${ }^{17}$

Even though the envelope and its content were only seen by the auxiliary who handed the material ready for use to the operators, due to the different consistencies of the materials the operators could not be completely blinded. 
Table 2. Descriptive univariated and adjusted Cox regression analysis between failures in occlusoproximal restorations and associated factors.

\begin{tabular}{|c|c|c|c|c|c|c|c|}
\hline \multirow{2}{*}{ Variable } & \multirow{2}{*}{$\begin{array}{c}\text { Success n } \\
(\%)\end{array}$} & \multirow{2}{*}{$\begin{array}{c}\text { Failures n } \\
\text { (\%) }\end{array}$} & \multirow{2}{*}{ Total } & HR Univariate & \multirow{2}{*}{ p-value* } & HR Ajusted & \multirow{2}{*}{$\mathrm{p}$-value } \\
\hline & & & & $95 \% \mathrm{Cl}$ & & $95 \% \mathrm{Cl}$ & \\
\hline \multicolumn{8}{|l|}{ Material } \\
\hline Ketac Molar - ref & $30(50.85)$ & $29(49.15)$ & 59 & & & & \\
\hline Vitro Molar & $20(34.48)$ & $38(65.52)$ & 58 & $1.48(0.91-2.4)$ & 0.11 & $1.60(0.98-2.62)$ & 0.058 \\
\hline \multicolumn{8}{|l|}{ Operator } \\
\hline 1 - ref & $29(45.31)$ & $35(54.69)$ & 64 & & & & \\
\hline 2 & $21(39.62)$ & $32(60.38)$ & 53 & $1.03(0.64-1.67)$ & 0.87 & - & - \\
\hline \multicolumn{8}{|l|}{ DMFT } \\
\hline 0-2 (low) - ref & $11(37.93)$ & $18(62.07)$ & 29 & & & & \\
\hline 3 (avarage) & $6(30)$ & $14(70)$ & 20 & $1.38(0.68-2.78)$ & 0.36 & - & - \\
\hline$>3$ (high) & $33(48.53)$ & $35(51.47)$ & 68 & $0.87(0.49-1.55)$ & 0.65 & - & - \\
\hline \multicolumn{8}{|l|}{ Contamination } \\
\hline Yes - ref & $42(40.78)$ & $61(59.22)$ & 103 & & & & \\
\hline No & $8(57.14)$ & $6(42.86)$ & 14 & $0.63(0.27-1.46)$ & 0.28 & - & - \\
\hline \multicolumn{8}{|l|}{ Oclusal contact } \\
\hline Yes - ref & $44(41.12)$ & $63(58.88)$ & 107 & & & & \\
\hline No & $6(60)$ & $4(40)$ & 10 & $0.62(0.22-1.71)$ & 0.36 & - & - \\
\hline \multicolumn{8}{|l|}{ Proximal contact } \\
\hline Yes - ref & $10(45.45)$ & $12(54.55)$ & 22 & & & & \\
\hline No & $40(42.11)$ & 55 (57.89) & 95 & $1.05(0.56-1.97)$ & 0.86 & - & - \\
\hline \multicolumn{8}{|l|}{$\mathrm{ARCH}$} \\
\hline Superior - ref & $26(50)$ & $26(50)$ & 52 & & & & \\
\hline Inferior & $24(36.92)$ & $41(63.08)$ & 65 & $1.32(0.80-2.16)$ & 0.26 & - & - \\
\hline \multicolumn{8}{|l|}{ Tooth } \\
\hline $1^{\circ}$ Molar - ref & $38(39.18)$ & $59(60.82)$ & 97 & & & & \\
\hline $2^{\circ}$ Molar & $12(60)$ & $8(40)$ & 20 & $0.53(0.25-1.12)$ & 0.09 & $0.61(0.22-1.74)$ & 0.36 \\
\hline \multicolumn{8}{|l|}{ Side } \\
\hline Right & $32(47.06)$ & $36(52.94)$ & 68 & & & & \\
\hline Left & 18(36.73) & $31(63.27)$ & 49 & $1.15(0.71-1.86)$ & 0.55 & - & - \\
\hline \multicolumn{8}{|l|}{ Surface } \\
\hline Occlusal-mesial - ref & $18(58.06)$ & $13(41.94)$ & 31 & & & & \\
\hline Occlusal-distal & $32(37.21)$ & $54(62.79)$ & 86 & $1.71(0.93-3.14)$ & 0.08 & $1.35(0.58-3.13)$ & 0.48 \\
\hline \multicolumn{8}{|l|}{ Sex } \\
\hline Feminine - ref & $28(45.16)$ & $34(54.84)$ & 62 & & & & \\
\hline Masculine & $22(40)$ & $33(60)$ & 55 & $1.12(0.69-1.81)$ & 0.62 & - & - \\
\hline \multicolumn{8}{|l|}{ Cavity volume } \\
\hline $0-3 \mathrm{~mm}^{3}-$ ref & $13(50)$ & $13(50)$ & 26 & & & & \\
\hline $3-6 \mathrm{~mm}^{3}$ & $17(41.46)$ & $24(58.54)$ & 41 & $1.19(0.60-2.34)$ & 0.61 & - & - \\
\hline$>6 \mathrm{~mm}^{3}$ & $20(40)$ & $30(60)$ & 50 & $0.99(0.57-1.91)$ & 0.98 & - & - \\
\hline Total & $50(42.74)$ & $67(57.26)$ & 117 & & & & \\
\hline
\end{tabular}

HR: Hazard ratio; $\mathrm{Cl}$ : Confidence interval; ${ }^{*} \mathrm{p}<0.05$. 


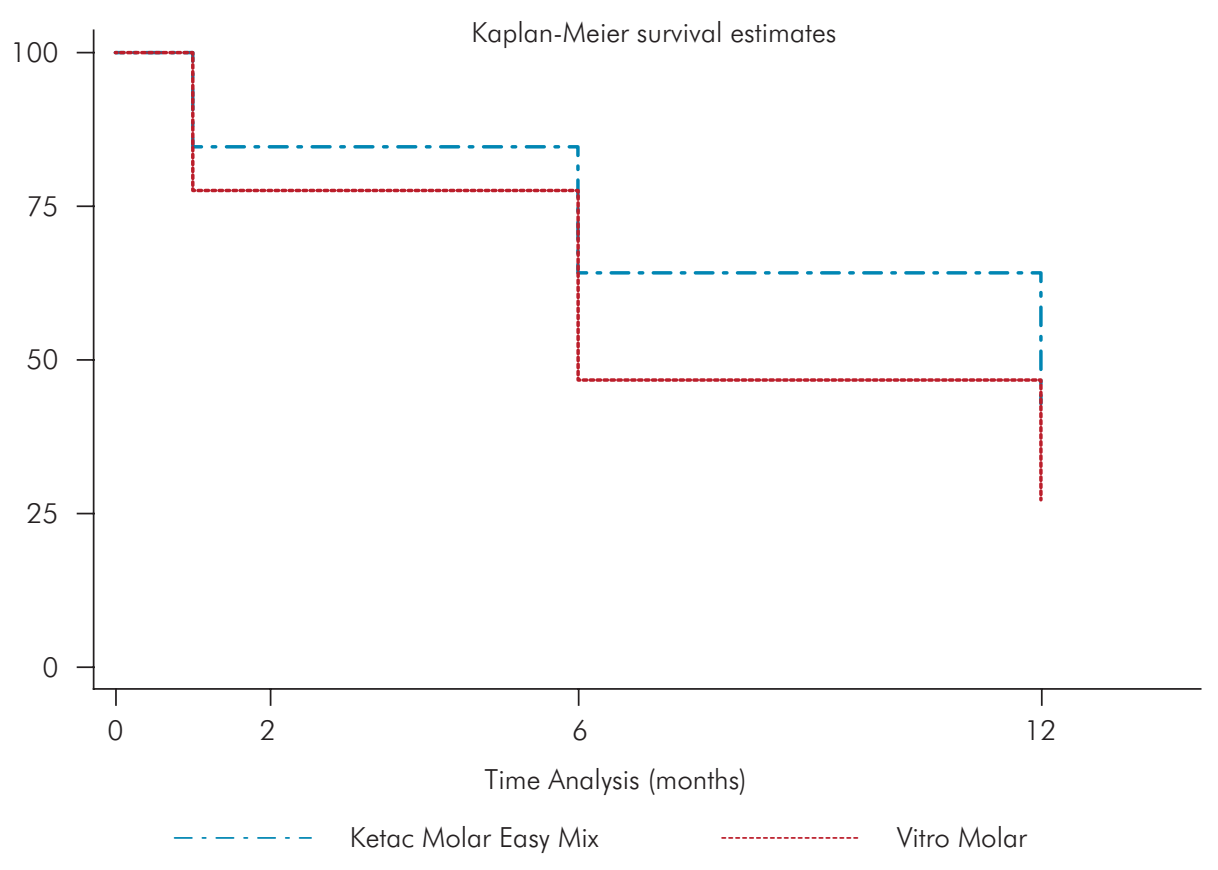

Figure 2.Kaplan-Meier survival estimates among the materials for occlusoproximal restorations in primary teeth (log-rank $p=0.058$ ).

Different operators can interfere in restorations' longevity, ${ }^{1,18,19,20}$ however, in this study an operator effect was not observed. Homogeneity between operators can be explained by the fact that they have the same level of experience and both received training in the ART approach prior to the beginning of this study.

Other factors such as the side of the tooth (right/left) and the restored surface (mesial or distal) had no influence on the longevity of restorations as described in other studies with primary teeth. ${ }^{21,22}$

A study reported that the presence or absence of the antagonist tooth had no effect on survival of restorations after 36 months of follow-up, ${ }^{20}$ as observed in the results of the present study. However, in another study, which investigated the longevity of ART restorations with the use of Ketac Molar Easymix (3M - ESPE) after two years, noted that the number of failed restorations was statistically significant in the presence of the antagonist tooth. ${ }^{19}$ Thus, it is suggested that this present study continues to monitor the interference of the antagonist tooth on the survival of the restorations. The same can be said in relation to the proximal contact; a study reported that the absence of proximal contact had a negative influence on the longevity of restorations after 3 years. ${ }^{23}$ This phenomenon could not be observed in this study.
Past caries experience $(\mathrm{dmft})$ is a factor that is directly related to the risk of developing new lesions. ${ }^{24}$ In this study, there was no statistical difference between the groups of low, average and high levels of caries experience. Moreover, Correa et al..$^{25}$ found that adolescents of 15 years of age with more than 5 decayed teeth had a higher risk of failed restorations. Our results may be explained by the increase in parental care in children with higher caries experience after the start of treatment. In addition, all children in the study received oral hygiene instructions, thus justifying the lack of difference in the longevity of restorations.

Other variables such as sex, contamination during restoration, arch, restored tooth and volume of the cavity did not show differences regarding the longevity of the restoration. The materials used did not show statistically significant differences. An in vitro study compared the hardness of the materials Ketac Molar and Vitro Molar, among others, and found that these materials showed very similar microhardness values after one day and one week. ${ }^{14}$

During this study, no difficulty was found in performing ART restorations in the school environment. Principals and teachers from the 19 schools involved in the study were more than willing to participate and provide a suitable place to carry 
out the treatments. The same was also reported in a study by Holmgren et al. ${ }^{26}$ This proves once again that ART restorations can in fact be applied in locations outside of the dental office setting.

\section{Conclusion}

After 12 months evaluation, no difference in the survival rate of ART occluso-proximal restorations was found between the tested materials (Ketac Molar EasyMix and Vitro Molar).

\section{References}

1. Frencken JE, Pilot T, Songpaisan $Y$, Phantumvanit P. Atraumatic restorative treatment (ART): rationale, technique, and development. J Public Health Dent. 1996;56(3 Spec No):135-40. https://doi.org/10.1111/j.1752-7325.1996.tb02423.x

2. Frencken JE, Holmgrem CJ. Atraumatic Restorative treatment for dental caries. Nijmegen: STI Book; 1999.

3. Schmalz G. ART: a method on its way into dentistry. Clin Oral Investig. 2012;16(5):1335-6. https://doi.org/10.1007/s00784-012-0815-0

4. Ismail Al. Reactor paper: minimal intervention techniques for dental caries. J Public Health Dent. 1996;56(3):155-60. https://doi.org/10.1111/j.1752-7325.1996.tb02427.x

5. Phantumvanit $P$, Songpaisan $Y$, Pilot T, Frencken JE. Atraumatic restorative treatment (ART): a three-year community field trial in Thailand: survival of one-surface restorations in the permanent dentition. J Public Health Dent. 1996;56(3):141-5. https://doi.org/10.1111/j.1752-7325.1996.tb02424.x

6. Wilson AD, Kent BE. A new translucent cement for dentistry; the glass ionomer cement. Br Dent J. 1972;132(4):133-5. https://doi.org/10.1038/sj.bdj.4802810

7. Mount GJ. A colour atlas of glass-ionomer cements. 2 nd ed. London: Martin Dunitz; 1994.

8. Ab-Ghani Z, Ngo H, Mclntyre J. Effect of remineralization/demineralization cycles on mineral profiles of Fuji IX Fast in vitro using electron probe microanalysis. Aust Dent J. 2007;52(4):276-81. https://doi.org/10.1111/j.1834-7819.2007.tb00502.x

9. Amorim RG, Leal SC, Frencken JE. Survival of atraumatic restorative treatment (ART) sealants and restorations: a meta-analysis. Clin Oral Investig. 2012;16(2):429-41. https://doi.org/10.1007/s00784-011-0513-3

10. Tedesco TK, Calvo AF, Lenzi TL, Hesse D, Guglielmi CA, Camargo LB et al. ART is an alternative for restoring occlusoproximal cavities in primary teeth - evidence from an

\section{Acknowledgments}

The authors would like to thank DFL (Rio de Janeiro, BR) for donating the materials and financially supporting ICO and ALBP, responsible for monitoring this trial. We would also like to thank the health service of the city of Barueri, in particular to Andrei Alvaro Barrichello and Fernanda Michellotti Cajado for their kind assistance. We are also very thankful to the operators of this trial: Nicole Verschaeren and Carlijn van der Cammen". updated systematic review and meta-analysis. Int J Paediatr Dent. 2017;27(3):201-9. https://doi.org/10.1111/ipd.12252

11. Raggio DP, Hesse D, Lenzi TL, Guglielmi CA, Braga MM. Is Atraumatic restorative treatment an option for restoring occlusoproximal caries lesions in primary teeth? A systematic review and meta-analysis. Int J Paediatr Dent. 2013;23(6):435-43. https://doi.org/10.1111/ipd.12013

12. Stona P, Bertella SM, Rockenbach MI, Holderbaum RM, Weber JB. Radiopacities of glass ionomer cements measured with direct digital radiographic system. J Dent Child (Chic). 2012;79(2):59-62.

13. Silva RC, Zuanon AC, Spolidorio DM, Campos JA. Antibacterial activity of four glass ionomer cements used in atraumatic restorative treatment. J Mater Sci Mater Med. 2007;18(9):1859-62. https://doi.org/10.1007/s10856-007-3035-4

14. Silva RC, Zuanon AC, Esberard RR, Candido MS, Machado JS. In vitro microhardness of glass ionomer cements. J Mater Sci Mater Med. 2007;18(1):139-42. https://doi.org/10.1007/s10856-006-0672-y

15. Silva RC, Zuanon AC. Surface roughness of glass ionomer cements indicated for atraumatic restorative treatment (ART). Braz Dent J. 2006;17(2):106-9. https://doi.org/10.1590/S0103-64402006000200004

16. Roeleveld AC, Amerongen WE, Mandari GJ. Influence of residual caries and cervical gaps on the survival rate of Class II glass ionomer restorations. Eur Arch Paediatr Dent. 2006;7(2):85-91. https://doi.org/10.1007/BF03320820

17. Lo EC, Holmgren CJ. Provision of Atraumatic Restorative Treatment (ART) restorations to Chinese pre-school children: 30-month evaluation. Int J Paediatr Dent. 2001;11(1):3-10. https://doi.org/10.1046/j.1365-263x.2001.00232.x

18. Frencken JE, Van '† Hof MA, Van Amerongen WE, Holmgren CJ. Effectiveness of single-surface ART restorations in the permanent dentition: a meta-analysis. J Dent Res. 2004;83(2):120-3. https://doi.org/10.1177/154405910408300207 
- One year Survival Rate of Ketac Molar versus Vitro Molar for occlusoproximal ART restorations: a RCT

19. Franca C, Colares V, Van Amerongen E. Two-year evaluation of the atraumatic restorative treatment approach in primary molars class I and II

restorations. Int J Paediatr Dent. 2011;21(4):249-53. https://doi.org/10.1111/j.1365-263X.2011.01125.x

20. Bonifácio CC, Hesse D, Raggio DP,

Bönecker M, Loveren C, Amerongen WE. The effect of GIC-brand on the survival rate of proximal-ART restorations. Int J Paediatr Dent. 2013;23(4):251-8. https://doi.org/10.1111/j.1365-263X.2012.01259.x

21. Bernardo M, Luis $H$, Martin MD, Leroux BG, Rue T, Leitão J et al. Survival and reasons for failure of amalgam versus composite posterior restorations placed in a randomized clinical trial. J Am Dent Assoc. 2007;138(6):775-83. https://doi.org/10.14219/jada.archive.2007.0265

22. Kemoli AM, Amerongen WE. Influence of the cavity-size on the survival rate of proximal ART restorations in primary molars. Int J Paediatr Dent. 2009;19(6):423-30. https://doi.org/10.1111/j.1365-263X.2009.01013.x
23. Gemert-Schriks MC, Amerongen WE, Ten Cate JM, Aartman IH. Three-year survival of single- and two-surface ART restorations in a high-caries child population. Clin Oral Investig. 2007;11(4):337-43. https://doi.org/10.1007/s00784-007-0138-8

24. Corrêa-Faria P, Paixão-Gonçalves S, Paiva SM, Pordeus IA. Incidence of dental caries in primary dentition and risk factors: a longitudinal study. Braz Oral Res. 2016;30(1):S1806-83242016000100254. https://doi.org/10.1590/1807-3107BOR-2016.vol30.0059

25. Correa MB, Peres MA, Peres KG, Horta BL, Barros AJ, Demarco FF. Do socioeconomic determinants affect the quality of posterior dental restorations? A multilevel approach. J Dent. 2013;41(11):960-7. https://doi.org/10.1016/i.jdent.2013.02.010

26. Holmgren CJ, Lo EC, Hu D, Wan H. ART restorations and sealants placed in Chinese school children: results after three years. Community Dent Oral Epidemiol. 2000;28(4):314-20. https://doi.org/10.1034/j.1600-0528.2000.280410.x 